\title{
Endoscopic saphenous vein harvesting and surgical site infections after coronary artery bypass surgery
}

\author{
Antonio Salsano, Giovanni Mariscalco, Francesco Santini \\ Division of Cardiac Surgery, IRCCS-Ospedale Policlinico San Martino, University of Genoa, Genoa, Italy \\ Correspondence to: Antonio Salsano, MD. Division of Cardiac Surgery, IRCCS-Ospedale Policlinico San Martino, University of Genoa, L.go Rosanna \\ Benzi 10, 16132 Genoa, Italy. Email: ant.salsano@gmail.com. \\ Comment on: Gulack BC, Kirkwood KA, Shi W, et al. Secondary surgical-site infection after coronary artery bypass grafting: A multi-institutional \\ prospective cohort study. J Thorac Cardiovasc Surg 2018;155:1555-62.e1.
}

Submitted Sep 07, 2018. Accepted for publication Sep 20, 2018.

doi: 10.21037/atm.2018.09.51

View this article at: http://dx.doi.org/10.21037/atm.2018.09.51

\section{Introduction}

Coronary artery bypass surgery (CABG) was introduced by Goetz in 1960, becoming one of the most performed surgical operations worldwide (1). CABG for myocardial revascularization is recommended for patients with severe stable and unstable coronary artery diseases, and it has been demonstrated to be superior to percutaneous coronary intervention (PCI) particularly in diabetic patients and complex coronary anatomy (2).

CABG operation can be performed with (on-pump CABG) or without (off-pump CABG) the aid of the cardiopulmonary bypass, consisting in connecting (or grafting) a healthy patient artery or vein to the narrowed coronary artery beyond the critical lesion, supplying the heart muscle with oxygen-rich blood.

Internal-thoracic-artery (mammary artery, IMA) graft ensures excellent long-term patency rates compared to the saphenous vein conduit (SVG) (>90\% for IMA versus $50 \%$ for SVG at 10 years) (3). This clinical benefit made the left mammary artery (LIMA) anastomosis to the LAD the graft of choice in CABG operation and the standard surgical approach $(2,3)$. Other conduits to use for other coronary anastomoses are still the subject of debate. Based on the survival advantage of LIMA to LAD anastomosis, some Authors claimed the bilateral internal thoracic artery (BIMA) grafting instead of (or in combination with) the radial artery and/or the saphenous vein as the preferable choice in surgical candidates affected by coronary artery diseases $(4,5)$.

An interim analysis at 5 years of the ART randomized controlled trial published in the NEJM by Taggart et al. failed to show superiority of surgical bypass with BIMA versus a single internal mammary artery (SIMA). In particular, sternal wound complications were observed in $3.5 \%$ of BIMA patients versus $1.9 \%$ in those with SIMA $(\mathrm{P}=0.005)$. BIMA also was associated with a $1.3 \%$ increase in early sternal wound reconstruction $(\mathrm{P}=0.002)$. However, mortality, stroke, myocardial infarction, and need for repeat revascularization were similar up to 5 years (4).

Among postoperative complications, mean 30-day mortality after CABG is $2.1 \%$, while stroke, gastrointestinal bleeding and renal failure requiring dialysis occur in less than $1.5 \%$ of operated patients (6). Infectious complications are observed in $5 \%$ to $21 \%$ of subjects, and are associated with consequent higher morbidity and mortality $(7,8)$. Incidence of sternal and leg wound infections after CABG reaches $8.4 \%$ and $7.0 \%$, respectively (8). The rate of surgical site infections (SSIs) after cardiac surgery can be reduced by adopting prevention practices that include modification of risk factors and surgical procedures techniques together with vigilance during the postoperative course (7).

In the study by Gulack et al. recently published in The Fournal of Thoracic and Cardiovascular Surgery the authors analyzed secondary SSIs of leg and groin in patients undergoing $\mathrm{CABG}$ with the use of SVG, and the processes of care associated with these infections (9). Among the data collected prospectively between February and October 2010 within the Cardiothoracic Surgical Trials Network (CTSN), 2,174 patients were selected which undergone CABG associated with SVG harvesting, subsequently followed up 
to 65 days postoperatively. Saphenous vein harvesting was endoscopic in $75 \%$ of the cases, and only $3 \%$ (65 cases) of the patients developed a secondary SSI. Among these cases, $12 \%$ were classified as deep and $88 \%$ as superficial SSIs, and $65 \%$ of these were diagnosed after the discharge from the index hospitalization. Secondary SSIs did not increase in-hospital mortality, although they were associated with a $78 \%$ readmission rate, with a median length of inhospital stay of 7 days. Gram positive bacteria accounted for $65 \%$ of isolates, being Staphylococcus aureus the most common identified microorganism. However, a non-trivial proportion of gram-negative bacteria suggested for routine wound cultures.

Finally, open SVG harvest [hazard ratio (HR) 2.12; 95\% CI, 1.28-3.48] demonstrated to be associated with the development of SSIs at multivariable analysis along with packed red blood cell transfusions (HR 1.13; 95\% CI, 1.05-1.22), and increased body mass index (HR 1.08; 95\% CI, 1.04-1.12).

\section{Endoscopic saphenous vein harvest}

Since its introduction in 1996 many expectations accompanied endoscopic vein harvesting (EVH) such as decrease leg wound morbidity, improved cosmetic results and enhanced patient satisfaction. EVH gained so much success as to represent the standard of care in USA where is now applied in about $80 \%$ all of CABG procedures (10). Despite the evidence of a beneficial impact of EVH on wound complications including leg wound infections, on the other hand, the long-term durability of the conduits harvested by this technique, is still debated $(11,12)$.

In a secondary analysis from the PREVENT IV trial following on 3,000 CABG patients subjected to vein harvesting by $\mathrm{EVH}$ versus open technique, a significant rate of veingraft failure (38\% open versus 46.7\% EVH; OR 1.45, 95\% CI, 1.20-1.76) and occlusion (33.8\% open versus $42.6 \%$ EVH; OR 1.47, 95\% CI, 1.20-1.79) were observed (13). Furthermore, EVH had a higher rate of death, myocardial infarction, or need for further revascularization $(20.2 \% \mathrm{vs}$. $17.4 \%$; adjusted hazard ratio, 1.22 ; $95 \%$ CI, 1.01-1.47) up to 3 years $(13)$.

Likewise, a sub-analysis of 1,471 patients, who underwent CABG with the use of SVG, comparing EVH and open techniques from the ROOBY trial, showed no significant differences between groups in terms of death or major perioperative complications including reoperation, new mechanical support, cardiac arrest, coma, stroke, or renal failure requiring dialysis (14). Interestingly enough however, in the subgroup of 894 patients with 1-year angiographic follow-up, SVG patency for EVH versus open technique was $74.5 \%$ and $85.2 \%$, respectively $(\mathrm{P}<0.0001)(14)$.

In opposition to the two above mentioned trials indeed not designed for EVH evaluation, a subsequent observational study by Williams et al. of 235,394 Medicare patients undergoing isolated CABG between 2003 and 2008 at 934 surgical US centers, showed no difference between $\mathrm{EVH}$ versus open technique in survival and the composite of death, myocardial infarction, or revascularization through 3 years, although a reduced rate of wound infections (adjusted HR 0.83, 95\% CI, 0.77-0.89) was registered. The vein graft damage hypothesis suspected for reduced patency or patient survival was therefore not supported (15). Relative to this issue, one might speculate that inhomogeneous results relative to vein graft damage and patency outcome could be influenced by the operators (EVH is generally performed by physician assistants in the USA while young residents do the procedure across Europe), different techniques or device technology advances $(12,16)$.

In summary, controversial evidences surround EVH. On one hand, endoscopic procedure seems to reduce wound-related complications, improve patient satisfaction, decrease postoperative pain, length of hospital stay, and use of wound-management resources. On the other, further randomized controlled trials are needed to clarify the issue of long-term graft patency.

\section{Surgical site infections after CABG}

Infectious complications represent a serious problem after cardiac surgery, and are associated with reduced survival, prolonged length of stay, and costs $(7,17,18)$.

We agree with Gulack et al. that it is impossible to clear infections, even if all the process of care would be implemented and strictly applied (9). Nonetheless, efforts in prevention are of paramount importance, aiming to infection rate decrease in the next coming years (17).

Screening glycaemia in all patients and glycemic control to maintain perioperative blood glucose levels $<200 \mathrm{mg} / \mathrm{dL}$, smoking cessation, correction of hypoalbuminemia before surgery, decolonization of nasal Stapbylococcus aureus carriage and intranasal mupirocin administration, adequate preoperative antibiotic prophylaxis with antimicrobial peak tissue levels at the time of skin incision, early weaning form ventilation, and removal of indwelling vascular and urinary catheters have been proved to significantly reduce SSIs after 
cardiac surgery $(7,17-22)$.

To avoid sternal infections, adopting proper techniques of wound closure is essential. Peri-sternal crisscross doublewire techniques, also known as figure-of-eight closure, seemed to be superior to standard interrupted steel wire closure with significant reduction in deep sternal wound infections $(16,17)$. Alternative techniques, such as described by Robicsek et al., where steel wires are woven parasternally in conjunction with standard wires, may be useful in case of multiple bone fracture $(17,22)$. Furthermore, the application of gentamicin-collagen sponges placed between the sternal edges before the end of the operation and effective surgical hemostasis to prevent re-sternotomy for bleeding resulted in significant reduction of deep sternal wound infections $(22,23)$.

Lastly, in order to decrease infectious complication after CABG, proper selection of conduits could make a difference.

BIMA is the most appropriate choice in young patients and/or in the absence of a $\mathrm{BMI}>30$, or diabetes with HbA1c greater than 7\% (24,25). Skeletonized internal thoracic artery dissection instead of pedicled graft should be preferred for the prevention of mediastinitis in diabetic patients or when BIMA are harvested $(21,24)$. In those circumstances in which BIMA is not recommended, radial artery and saphenous vein may still represent valuable options. EVH compared to open technique is associated with two- to three-fold improvements in the rate of wound related complications and infections (12). In view of these observations, endoscopic technique could represent the technique of choice for SVG harvesting, proven graft patency is not affected by the procedure.

\section{Acknowledgements}

None.

\section{Footnote}

Conflicts of Interest: The authors have no conflicts of interest to declare.

\section{References}

1. Endo M. The history and evolution of coronary artery bypass grafting. Nihon Geka Gakkai Zasshi 2000;101:827-32.

2. Neumann FJ, Sousa-Uva M, Ahlsson A, et al. 2018 ESC/ EACTS Guidelines on myocardial revascularization. Eur
Heart J 2018. [Epub ahead of print]

3. Fitzgibbon GM, Kafka HP, Leach AJ, et al. Coronary bypass graft fate and patient outcome: angiographic followup of 5,065 grafts related to survival and reoperation in 1,388 patients during 25 years. J Am Coll Cardiol 1996;28:616-26.

4. Taggart DP, Altman DG, Gray AM, et al. Randomized Trial of Bilateral versus Single Internal-Thoracic-Artery Grafts. N Engl J Med 2016;375:2540-9.

5. Gaudino M, Puskas JD, Di Franco A, et al. Three Arterial Grafts Improve Late Survival: A MetaAnalysis of Propensity-Matched Studies. Circulation 2017;135:1036-44.

6. Nalysnyk L, Fahrbach K, Reynolds MW, et al. Adverse events in coronary artery bypass graft $(\mathrm{CABG})$ trials: a systematic review and analysis. Heart 2003;89:767-72.

7. Cove ME, Spelman DW, MacLaren G. Infectious complications of cardiac surgery: a clinical review. J Cardiothorac Vasc Anesth 2012;26:1094-100.

8. Blasco-Colmenares E, Perl TM, Guallar E, et al. Aspirin plus clopidogrel and risk of infection after coronary artery bypass surgery. Arch Intern Med 2009;169:788-96.

9. Gulack BC, Kirkwood KA, Shi W, et al. Secondary surgical-site infection after coronary artery bypass grafting: A multi-institutional prospective cohort study. J Thorac Cardiovasc Surg 2018;155:1555-62.e1.

10. Accord R, Maessen J. Endoscopic vein harvesting for coronary bypass grafting: a blessing or a trojan horse? Cardiol Res Pract 2011;2011:813512.

11. Sastry P, Rivinius R, Harvey R, et al. The influence of endoscopic vein harvesting on outcomes after coronary bypass grafting: a meta-analysis of 267,525 patients. Eur J Cardiothorac Surg 2013;44:980-9.

12. Kodia K, Patel S, Weber MP, et al. Graft patency after open versus endoscopic saphenous vein harvest in coronary artery bypass grafting surgery: a systematic review and meta-analysis. Ann Cardiothorac Surg 2018;7:586-97.

13. Lopes RD, Hafley GE, Allen KB, et al. Endoscopic versus open vein-graft harvesting in coronary-artery bypass surgery. N Engl J Med 2009;361:235-44.

14. Zenati MA, Shroyer AL, Collins JF, et al. Impact of endoscopic versus open saphenous vein harvest technique on late coronary artery bypass grafting patient outcomes in the ROOBY (Randomized On/Off Bypass) Trial. J Thorac Cardiovasc Surg 2011;141:338-44.

15. Williams JB, Peterson ED, Brennan JM, et al. Association between endoscopic vs open vein-graft harvesting and mortality, wound complications, and cardiovascular 
events in patients undergoing CABG surgery. JAMA 2012;308:475-84.

16. Andreas M, Wiedemann D, Stasek S, et al. Endoscopic vein harvesting is influenced by patient-related risk factors and may be of specific benefit in female patients. Interact Cardiovasc Thorac Surg 2013;17:603-7.

17. Lazar HL, Salm TV, Engelman R, et al. Prevention and management of sternal wound infections. J Thorac Cardiovasc Surg 2016;152:962-72.

18. Haycock C, Laser C, Keuth J, et al. Implementing evidence-based practice findings to decrease postoperative sternal wound infections following open heart surgery. J Cardiovasc Nurs 2005;20:299-305.

19. O'Hara LM, Thom KA, Preas MA. Update to the Centers for Disease Control and Prevention and the Healthcare Infection ControlPractices Advisory Committee Guideline for the Prevention of Surgical Site Infection (2017): A summary, review, and strategies for implementation. Am J Infect Control 2018;46:602-9.

20. Navaratnarajah M, Rea R, Evans R, et al. Effect of

Cite this article as: Salsano A, Mariscalco G, Santini F. Endoscopic saphenous vein harvesting and surgical site infections after coronary artery bypass surgery. Ann Transl Med 2018;6(Suppl 1):S37. doi: 10.21037/atm.2018.09.51 glycaemic control on complications following cardiac surgery: literature review. J Cardiothorac Surg 2018;13:10.

21. Abu-Omar Y, Kocher GJ, Bosco P, et al. European Association for Cardio-Thoracic Surgery expert consensus statement on the prevention and management of mediastinitis. Eur J Cardiothorac Surg 2017;51:10-29.

22. Vos RJ, Van Putte BP, Kloppenburg GTL. Prevention of deep sternal wound infection in cardiac surgery: a literature review. J Hosp Infect 2018;100:411-20.

23. Boeken U, Eisner J, Feindt P, et al. Does the time of resternotomy for bleeding have any influence on the incidence of sternal infections, septic courses or further complications? Thorac Cardiovasc Surg 2001;49:45-8.

24. Savage EB, Grab JD, O'Brien SM, et al. Use of both internal thoracic arteries in diabetic patients increases deep sternal wound infection. Ann Thorac Surg 2007;83:1002-6.

25. Rubino AS, Gatti G, Reichart D, et al. Early Outcome of Bilateral Versus Single Internal Mammary Artery Grafting in the Elderly. Ann Thorac Surg 2018;105:1717-23. 